\title{
Cross species comparison of C/EBP $\alpha$ and PPAR $\gamma$ profiles in mouse and human adipocytes reveals interdependent retention of binding sites
}

\author{
Søren F Schmidt ${ }^{1 \dagger}$, Mette Jørgensen ${ }^{2 \dagger}$, Yun Chen ${ }^{2}$, Ronni Nielsen ${ }^{1}$, Albin Sandelin²*, Susanne Mandrup ${ }^{2^{*}}$
}

\begin{abstract}
Background: The transcription factors peroxisome proliferator activated receptor $\gamma$ (PPAR $\gamma$ ) and CCAAT/enhancer binding protein $\alpha(C / E B P \alpha)$ are key transcriptional regulators of adipocyte differentiation and function. We and others have previously shown that binding sites of these two transcription factors show a high degree of overlap and are associated with the majority of genes upregulated during differentiation of murine 3T3-L1 adipocytes.

Results: Here we have mapped all binding sites of C/EBP $\alpha$ and PPAR $\gamma$ in human SGBS adipocytes and compared these with the genome-wide profiles from mouse adipocytes to systematically investigate what biological features correlate with retention of sites in orthologous regions between mouse and human. Despite a limited interspecies retention of binding sites, several biological features make sites more likely to be retained. First, co-binding of PPAR $\gamma$ and C/EBP $\alpha$ in mouse is the most powerful predictor of retention of the corresponding binding sites in human. Second, vicinity to genes highly upregulated during adipogenesis significantly increases retention. Third, the presence of C/EBP $\alpha$ consensus sites correlate with retention of both factors, indicating that C/EBP $\alpha$ facilitates recruitment of PPAR $\gamma$. Fourth, retention correlates with overall sequence conservation within the binding regions independent of C/EBP $\alpha$ and PPAR $\gamma$ sequence patterns, indicating that other transcription factors work cooperatively with these two key transcription factors.

Conclusions: This study provides a comprehensive and systematic analysis of what biological features impact on retention of binding sites between human and mouse. Specifically, we show that the binding of C/EBP $\alpha$ and PPARy in adipocytes have evolved in a highly interdependent manner, indicating a significant cooperativity between these two transcription factors.
\end{abstract}

\section{Background}

The adipose tissue plays a central role in maintaining whole body lipid and glucose homeostasis as well as insulin sensitivity $[1,2]$. Adipocytes are derived from fibroblastic precursors in the adipose tissue through a tightly regulated differentiation process. The molecular basis for the regulation of adipogenesis has been studied extensively in vitro using a variety of preadipocyte cell culture models. In particular, studies of the 3T3-L1 cell line derived from

\footnotetext{
*Correspondence: albin@binf.ku.dk; s.mandrup@bmb.sdu.dk

+ Contributed equally

'Department of Biochemistry and Molecular Biology, University of Southern Denmark, Campusvej 55, DK-5230 Odense M, Denmark

${ }^{2}$ The Bioinformatics Centre, Department of Biology and Biomedical Research and Innovation Centre, Copenhagen University, Ole Maaløs Vej 5, DK-2200,

Copenhagen N, Denmark

Full list of author information is available at the end of the article
}

mouse embryo fibroblasts [3] have been valuable for gaining insight into the ordered cascade of molecular events required for adipogenesis [4-6]. More recently, human cell culture models have become available including the SGBS cell line derived from preadipocytes from a patient with Simpson-Golabi-Behmel syndrome [7].

The transcription factor peroxisome proliferator activated receptor (PPAR $\gamma$ ) is a key regulator of adipogenesis, required for in vitro as well as in vivo differentiation of adipocytes [8,9]. In addition to PPAR $\gamma$, a number of other important transcriptional regulators of adipocyte differentiation have been identified [6], including members of the CCAAT/enhancer binding protein (C/EBP) family [10-12]. $\mathrm{C} / \mathrm{EBP} \alpha$ is induced late in adipocyte differentiation and is known to cooperate with PPAR $\gamma$ in induction of at least a subset of adipocyte-specific genes. In addition, these two

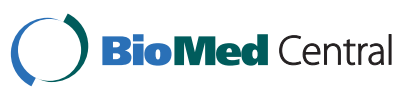


factors induce the expression of each other [13,14]. Two other members of the C/EBP family, C/EBP $\beta$ and $-\delta$, are directly involved in the transcriptional induction of PPAR $\gamma$ and $\mathrm{C} / \mathrm{EBP} \alpha$ [6].

We recently used chromatin immunoprecipitation (ChIP) combined with deep sequencing (ChIP-seq) to generate genome-wide maps of the binding sites of $\operatorname{PPAR} \gamma$ and its heterodimerization partner retinoid $\times$ receptor (RXR) during differentiation of 3T3-L1 adipocytes [15]. In addition, we profiled RNA polymerase II (RNAPII) occupancy to measure active transcription at different time points during differentiation. This study revealed that PPAR $\gamma:$ RXR binding was highly enriched in the vicinity of genes upregulated during adipogenesis. In fact, the majority (75\%) of all highly up-regulated genes have PPAR $\gamma:$ RXR binding in the immediate vicinity [15]. Similarly, Lazar and colleagues [16] and others $[17,18]$ used ChIP in combination with hybridization to genomic tiling microarrays (ChIP-chip) or cloning followed by sequencing (ChIP-PET) to map PPAR $\gamma$ binding sites in 3T3-L1 adipocytes (reviewed in [19]). Intriguingly, these studies have revealed that the C/EBP $\alpha$ consensus site is highly over-represented under the binding regions of PPAR $\gamma$. Lazar and colleagues profiled C/EBP $\alpha$ binding sites in mature 3T3-L1 adipocytes and found a remarkable overlap between C/EBP $\alpha$ and PPAR $\gamma$ binding ( $>60 \%$ of all PPAR $\gamma$ sites) on a genome-wide scale [16]. Importantly, $60 \%$ of the genes induced during adipogenesis have both $\mathrm{C} / \mathrm{EBP} \alpha$ and PPAR $\gamma$ binding sites within $50 \mathrm{~kb}$ of a transcription start site (TSS), and knockdown studies indicated that both $\mathrm{C} / \mathrm{EBP} \alpha$ and PPAR $\gamma$ are required for robust gene expression of a few selected adipocyte specific target genes. Cumulatively, these results indicate that both PPAR $\gamma$ and $\mathrm{C} / \mathrm{EBP} \alpha$ are directly involved in the activation of the majority of adipocyte-specific genes and that they cooperate through binding to adjacent sites on DNA.

Genome-wide profiling has also made it possible to study the evolution of gene regulation by mapping the sites for the same transcription factors in different species. This is typically done by aligning genomes of the two species and tabulating the number of detected sites in one species that are in the corresponding region in the other species. This means that a genomic region might be highly conserved in terms of nucleotides but may or may not bind the transcription factor in question in both species. To distinguish between genome sequence conservation and transcription factor binding site conservation, we will use the word "retention" to describe binding sites that are present in both species in the corresponding genomic region.

Notably, whereas the functional gene targets of a particular transcription factor are generally well conserved between species, it has been shown that the majority of binding sites for all transcription factors investigated to date are species-specific [20-25], reviewed in [26]. This is surprising given that sequence conservation has been successfully used to enhance regulatory site prediction in proximal promoters (phylogenetic foot printing) [27,28]; however, this might reflect that these older studies were focused on limited sets of sites often located in tissuespecific promoters, while genome-wide methods, such as ChIP-seq, are independent of previous annotations. Consistent with the species specificity of transcription factor binding sites, Rosen and colleagues recently compared PPAR $\gamma$ binding in 3T3-L1 adipocytes and in vitro differentiated primary human adipose stromal cells (hASC), and found that only $21.3 \%$ of the murine binding sites were retained in human adipocytes. By contrast, the association of PPAR $\gamma$ with adipocyte gene regulation appeared to be better retained than the specific binding sites, and the overall gene expression profiles were well conserved [21]. Rosen and colleagues also showed that genes associated with a conserved PPAR $\gamma$ binding site are more likely to be upregulated during adipogenesis than genes associated with a species specific site [21], indicating that retention of PPAR $\gamma$ binding is increased near upregulated genes.

While previous reports agree that retention of transcription factor binding sites is limited, systematic analysis of the biological features determining whether a site is retained or not has not been performed. In particular, the interdependence between retention of the transcription factor binding sites of two transcription factors has not been investigated. Here, we used ChIP-seq to generate genome-wide binding profiles of C/EBP $\alpha$ and PPAR $\gamma$ in human SGBS adipocytes, compared these to previously published profiles in mouse 3T3-L1 adipocytes [15,16], and systematically studied what features affect whether a binding site is retained between species or not.

We find that PPAR $\gamma$ binding sites have higher retention near genes upregulated during adipogenesis, and that regions bound by both factors are even more likely to be retained. Interestingly, PPAR $\gamma$ binding site retention in these co-bound regions is increased by the presence of a $C / E B P \alpha$ consensus site, suggesting that $\mathrm{C} / \mathrm{EBP} \alpha$ may facilitate PPAR $\gamma$ binding to DNA. At the same time, and independent of C/EBP $\alpha$ and PPAR $\gamma$ sequence patterns, sequence conservation in the larger region surrounding the actual binding sites has a positive impact on retention of both $\mathrm{C} / \mathrm{EBP} \alpha$ and PPAR $\gamma$ binding sites, indicating that other DNA sequence patterns also affect binding of these two factors to DNA.

\section{Results}

Genome-wide mapping of C/EBP $\alpha$ and PPAR $\gamma$ binding in human SGBS adipocytes

To compare C/EBP $\alpha$ and PPAR $\gamma$ binding in mouse and human adipocytes, we used ChIP-seq to generate 
genome-wide profiles of $\mathrm{C} / \mathrm{EBP} \alpha$ and PPAR $\gamma$ binding in human SGBS adipocytes. Mapped ChIP tags were analyzed using peak finder methods, which identify regions enriched for ChIP tags. For simplicity, we will refer to such regions as "sites", but it is important to notice that these regions are typically 100-400 nt wide (up to 1000 nt wide in ChIP-chip studies) and thus several magnitudes larger than the actual binding site (typically 5$20 \mathrm{nt}$ ). We used the MACS peak finder [29] to identify regions consistently bound by $\mathrm{C} / \mathrm{EBP} \alpha$ and $\mathrm{PPAR} \gamma$ in two biologically independent experiments. We detected $52,733 \mathrm{C} / \mathrm{EBP} \alpha$ and 23,328 PPAR $\gamma$ binding sites in human SGBS adipocytes, and in accordance with previous findings in mouse [16], we found that $49.5 \%$ of PPAR $\gamma$ binding sites are also bound by $\mathrm{C} / \mathrm{EBP} \alpha$. The number of PPAR $\gamma$ sites is comparable to the 39,968 sites recently reported by Rosen and colleagues for in vitro differentiated hASCs [21]. However, the numbers are notably higher than the corresponding numbers in 3T3L1 cells, where 16,760 [16] and 15,461 (this study) $\mathrm{C} / \mathrm{EBP} \alpha$ sites and 5299 [16] and 6952 [15] PPAR $\gamma$ sites were reported. It remains to be investigated whether this represents a true species-specific difference, or whether this is more related to technical issues such as antibody specificity or cell culture conditions.

We have previously reported that binding profiles of PPAR $\gamma$ in 3T3-L1 s vary significantly between individual experiments and laboratories [19]. Similarly, when comparing the PPAR $\gamma$ sites of our own ChIP-seq study [15], the ChIP-seq study of Rosen and colleagues [21], and the ChIP-Chip study by Lazar and colleagues [16] only approximately $50 \%$ of the detected peaks were shared between 2 experiments, and only 2025 of a total of 12,136 peaks $(16,6 \%)$ were shared between all 3 experiments (Additional file 1 Fig. S1). To infer high confidence binding sites occupied by $\mathrm{C} / \mathrm{EBP} \alpha$ and PPAR $\gamma$ in mouse adipocytes, we used only the $8688 \mathrm{C} / \mathrm{EBP} \alpha$ and $3481 \mathrm{PPAR} \gamma$ binding sites from our ChIP-seq analysis that overlap with the previously published ChIP-chip sites [16]. The inferred high confidence $\mathrm{C} / \mathrm{EBP} \alpha$ and PPAR $\gamma$ binding sites have a smaller overlap of $36 \%$ (Figure 1A), compared with the previously reported $>60 \%$ [16]. Possible explanations may be the higher resolution of the ChIP-seq data as well as the fact that the number of high confidence sites used is lower.

\section{Correlating binding sites with gene expression patterns during adipogenesis}

We previously identified 1650 genes which were differentially expressed during 3T3-L1 adipogenesis as assessed by RNAPII association to the respective genes [15]. In that study, these genes were clustered in 5 different expression clusters depending on their relative expression profile during differentiation. For the purpose of this study we combined the two clusters containing genes downregulated during 3T3-L1 adipogenesis. This resulted in four new clusters: downregulated (1), transiently upregulated (2), moderately upregulated (3), and highly upregulated (4) (Figure 1B). For each gene belonging to a particular cluster, we divided the genomic region at +/- $100 \mathrm{~kb}$ around TSS into $10 \mathrm{~kb}$ intervals ("bins") and counted the number of mouse PPAR $\gamma$ binding sites within each such intervals. The PPAR $\gamma$ binding sites are enriched in the vicinity of all regulated genes compared to randomly selected regions (Figure 1C). Moreover and consistent with previous findings $[15,16]$, PPAR $\gamma$ binding sites in mouse adipocytes are highly enriched in the vicinity of genes moderately (3) and highly (4) upregulated during adipogenesis (Figure 1C). Similarly, PPAR $\gamma$ binding sites are also enriched in the vicinity of the human gene orthologs of the genes in these clusters (Figure $1 \mathrm{C}$ ), consistent with a role for PPAR $\gamma$ in the regulation of these genes in SGBS adipocytes.

\section{Measuring retention of mouse binding sites in human}

To study the retention of $\mathrm{C} / \mathrm{EBP} \alpha$ and PPAR $\gamma$ binding sites between mouse and human adipocytes, we used human-mouse genome alignments [30] to identify human genome regions orthologous to $\mathrm{C} / \mathrm{EBP} \alpha$ and PPAR $\gamma$ sites in mouse (see Methods). To make sure that the sites were orthologous at genome sequence level, a mouse site had to map to a single location in the human genome, which in turn had to map back to the original site in mouse. We did not address site loss or gain due to large deletions or insertions in one species. This resulted in $2176 \mathrm{PPAR} \gamma$ and $4899 \mathrm{C} / \mathrm{EBP} \alpha$ mouse sites that could be mapped to the human genome $(62.5 \%$ and $56.3 \%$ of all detected mouse PPAR $\gamma$ and $\mathrm{C} / \mathrm{EBP} \alpha$ binding sites, respectively).

We defined a mouse binding site as retained when its corresponding human coordinates overlapped a human binding site (Figure 2). A potential problem with this approach is that it will be dependent on the thresholds used in peak finding, and it also models average transcription factor binding in a cell population as on-off events, which is a large simplification. Since the relative number of ChIP'ed sequence tags in a region will indicate the average "strength" of the binding, i.e. average occupancy time, we also measured retention in a complementary way. Thus, in a human genomic region corresponding to a mouse binding site, we counted the number of ChIP'ed tags from the transcription factor in question and calculated a log(fold-change) enrichment relative to the genomic background in human (see Methods) (Figure 2). The advantage of this approach compared to the above method is that the retention of sites will not be on-off (binary) events but a continuous measure, and weaker cases of retention may be discovered. We will refer to these two methods to measure 
A

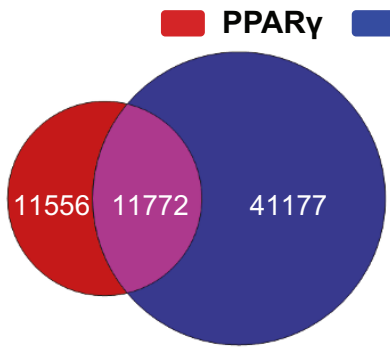

Human SGBS adipocytes

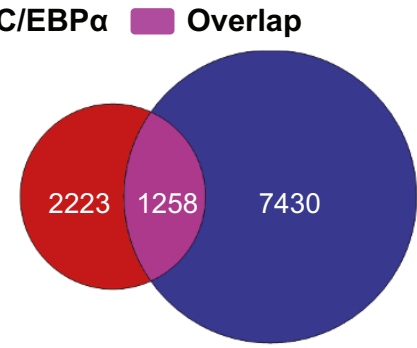

Mouse 3T3-L1 adipocytes
C

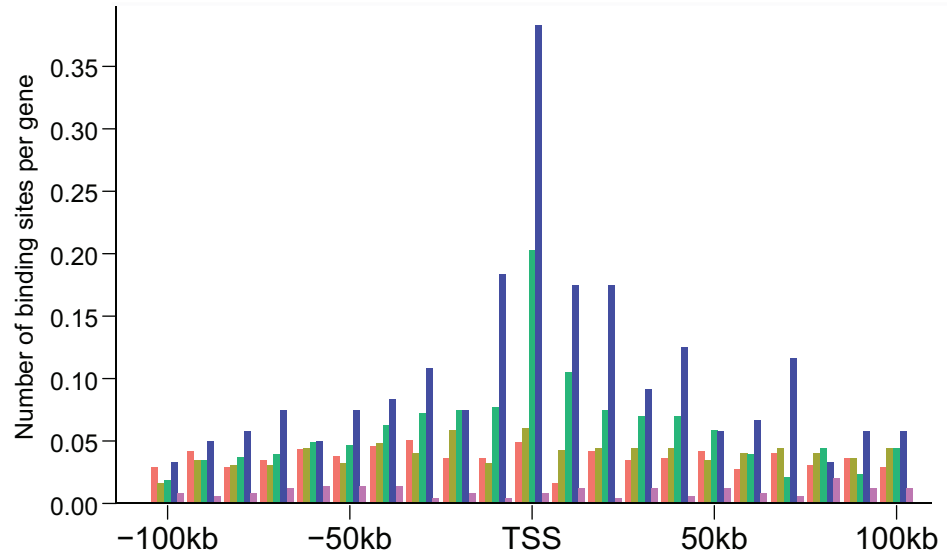

PPARy binding in human

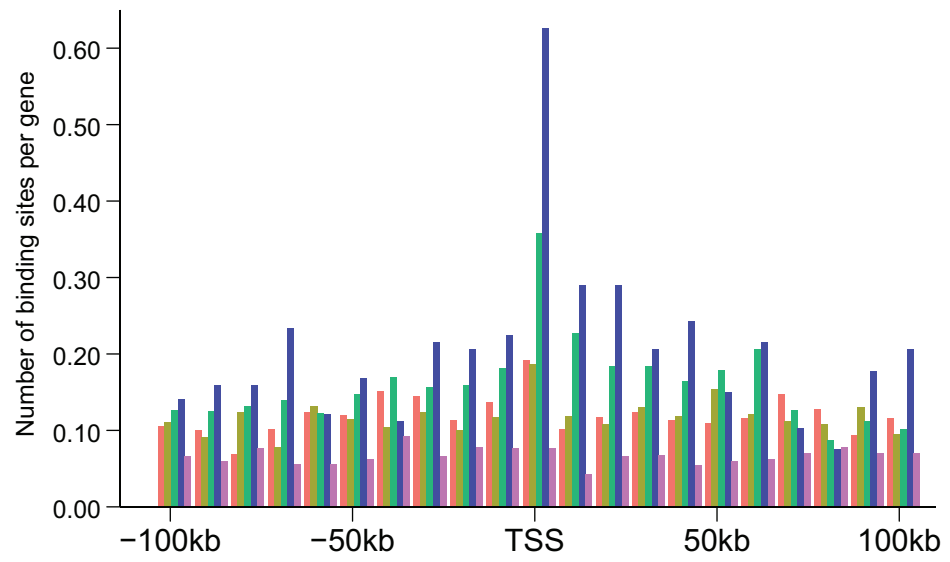

B
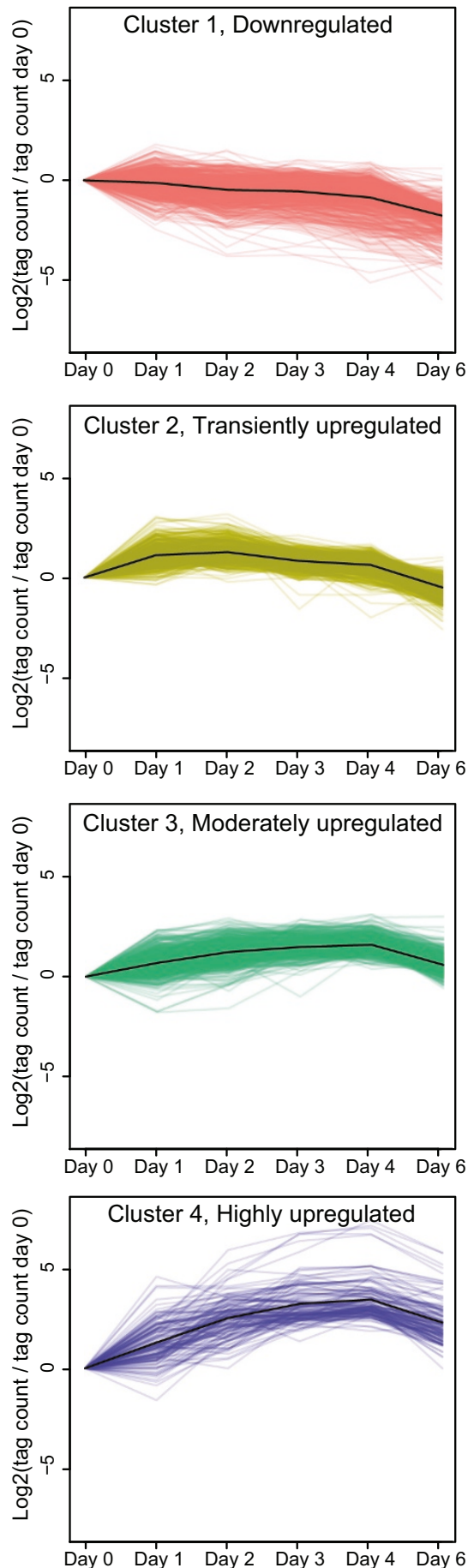

Figure 1 Genome-wide mapping of C/EBP $\alpha$ and PPAR $\gamma$ binding in human SGBS adipocytes. (A) The number of C/EBP $\alpha$ and PPAR $\gamma$ sites in SGBS and 3T3-L1 adipocytes. Results are shown as Venn diagrams representing the number of binding sites for C/EBP $\alpha$ only (blue), PPAR only (red), and overlapping binding sites (purple). (B) Expression clusters of genes based on their changes in RNAPII occupancy during 3T3-L1 adipogenesis. The clusters correspond to genes that are (1) downregulated, (2) transiently upregulated, (3) moderately upregulated or (4) highly upregulated. (C) Distribution of PPARy sites relative to TSS of downregulated genes (magenta), transiently upregulated genes (yellow), moderately upregulated genes (green), highly upregulated genes (blue) and randomly selected regions (purple), in mouse and human. The region +/- $100 \mathrm{~kb}$ around each TSS was divided into $10 \mathrm{~kb}$ regions, and the mean number of sites in each region is indicated in the bar plots. 


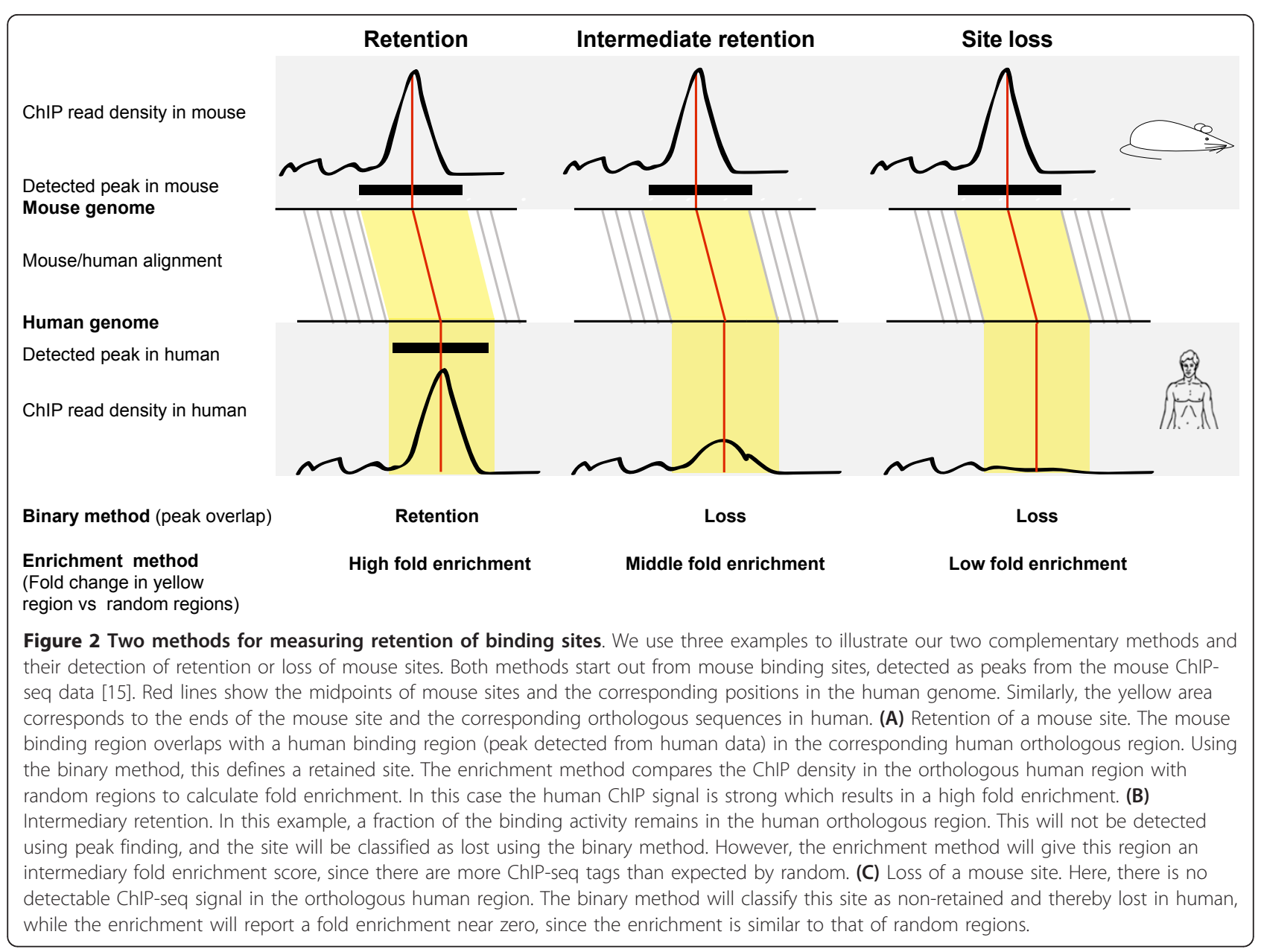

the amount of site retention as the binary and enrichment method, respectively.

Using the binary method, we find that most binding sites are species specific; only $19.5 \%$ of $\mathrm{C} / \mathrm{EBP} \alpha$ and $16.9 \%$ of PPAR $\gamma$ binding sites in mouse adipocytes are retained in human adipocytes (Figure 3A). The enrichment analysis supports the binary analysis in that most of the enrichment values for both factors are located around 0 , which is expected by random, and in that many of the mouse sites map to human regions that are totally devoid of ChIP-seq tags (negative fold change) (Figure 3B).

Conversely, there are sites that we with high confidence can label as retained between species. We noticed that there are larger genomic regions in which the majority of C/EBP $\alpha$ and PPAR $\gamma$ binding are retained as exemplified by the PPARG2 locus (Figure 3C). Given the crucial role of PPAR $\gamma$ in adipocyte differentiation, it is tempting to suggest that the reason that these particular sites are retained is their importance for the overall regulatory regime, since they likely regulate a key transcription factor. Prompted by this observation, we proceeded to systematically identify biological features that are positively correlated with increased retention of PPAR $\gamma$ and $\mathrm{C} / \mathrm{EBP} \alpha$ sites, with the hope of increasing our understanding of adipocyte gene regulation.

\section{Retention of PPAR $\gamma$ binding sites is increased in the vicinity of genes up-regulated during 3T3-L1 adipogenesis}

Several studies have reported that retention of binding sites is generally higher in the vicinity of putative key target genes [20-25]. However, species-specific binding sites are also enriched in these regions, and no studies have addressed whether the relative retention of binding sites (i.e the fraction of the sites in a mouse region that is retained vs. lost in human) is increased in the vicinity of putative target genes of the transcription factor. The assignment of target genes for binding sites is not trivial. Most studies agree that sites proximal to a gene are more likely to regulate the gene in question but this is not an absolute truth. In light of this, we used a combination of distance and gene expression to associate genes and binding sites. Thus, to systematically investigate how binding 


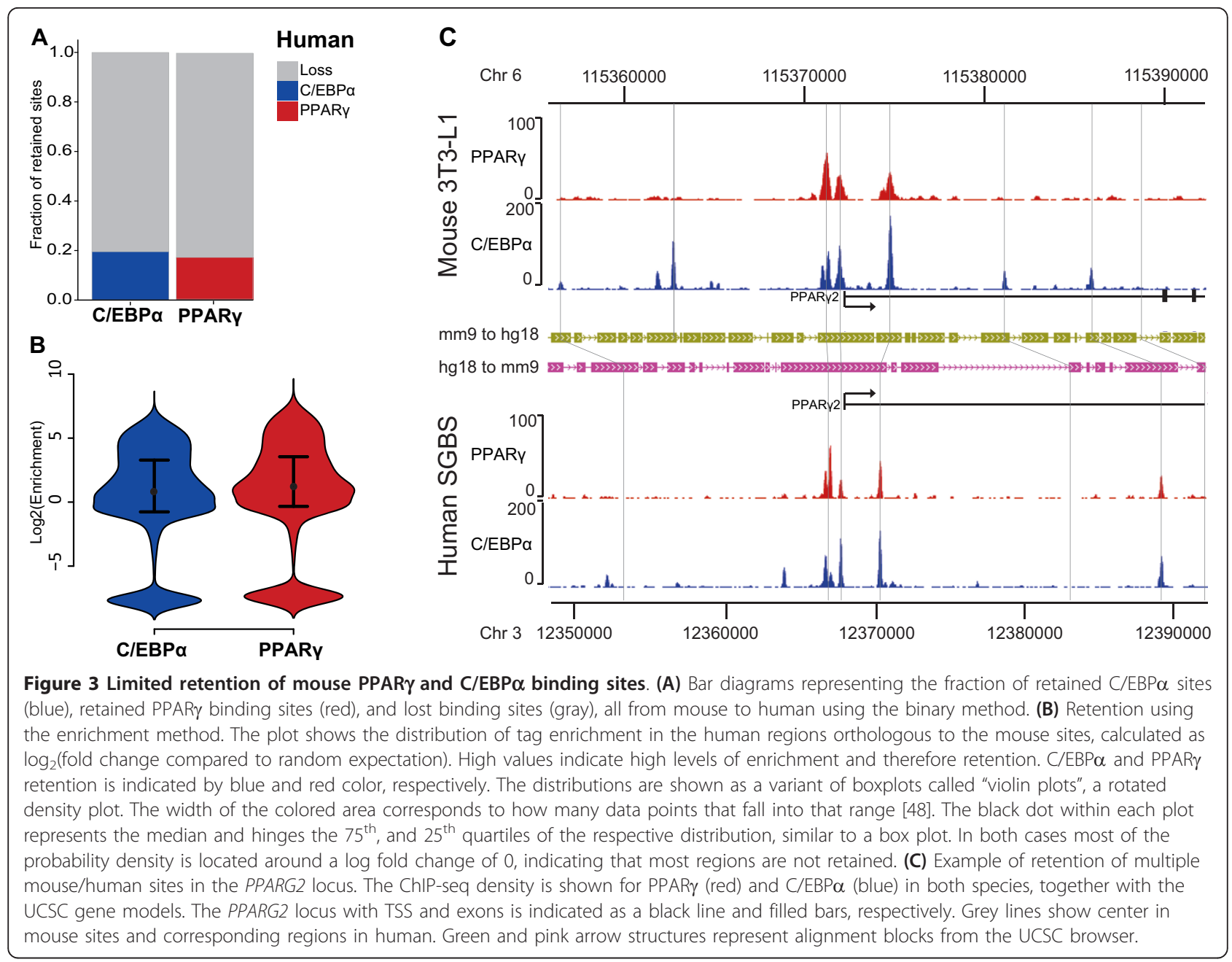

site retention is affected by the vicinity to putative target genes, we labeled sites in the following way. First, for each binding site, we located the closest gene TSS. If this TSS was closer than $100 \mathrm{~kb}$, and the gene was within one of the pre-defined expression clusters shown in Figure 1 (a differentially expressed gene), the site was labeled with the corresponding cluster number (cluster 1 to 4 ). Sites where the closest TSS was closer than $100 \mathrm{~kb}$ but the gene was not part of any expression cluster (a gene with no measurable difference in expression during adipogenesis) were defined to belong to a new cluster, cluster 5 ("constitutive genes"). Finally, all sites with no gene TSS within $100 \mathrm{~kb}$ were defined to belong to a new cluster: cluster 6 ("distal sites"). There are obviously many ways to assign binding sites to putative target genes. However, the overall results described below are not specific to the cluster assignment method used. For instance, assigning sites to expression clusters only based on the identity of the closest gene gave very similar results (data not shown).
We then measured the fraction of mouse $\mathrm{C} / \mathrm{EBP} \alpha$ and PPAR $\gamma$ binding sites that was retained and lost in human. The fraction of retained PPAR $\gamma$ binding sites is significantly higher in the vicinity of genes that are moderately or highly upregulated (clusters 3 and 4) compared to all other binding sites (Fischer Exact Test, $\left.P<2.2^{*} 10^{\wedge}-16\right)$. Conversely, retention of $\mathrm{C} / \mathrm{EBP} \alpha$ sites appears to be slightly increased in the vicinity of highly upregulated genes (cluster 4) compared to all other binding sites, but the difference is not statistically significant (Fischer Exact Test, $P=0.1$ ) (Figure 4A). This is also true if assessing retention by the enrichment method (Wilcoxon test; C/EBP $\alpha$, cluster 4 vs. all other clusters, $P=0.056$; PPAR $\gamma$ cluster 4 vs. all other clusters, $P=2.9^{*} 10^{\wedge}-5$; PPAR $\gamma$ cluster 3 vs. clusters $1+2+5$ $+6, P=4.55^{*} 10^{\wedge}-5$ ) (Figure $4 \mathrm{~B}$ ). Further analysis of the enrichment values showed that also mouse $\mathrm{C} / \mathrm{EBP} \alpha$ and PPAR $\gamma$ binding sites associated with moderately and highly upregulated genes (cluster 3 and 4) have on average more ChIP tags (i.e. display stronger binding) than 


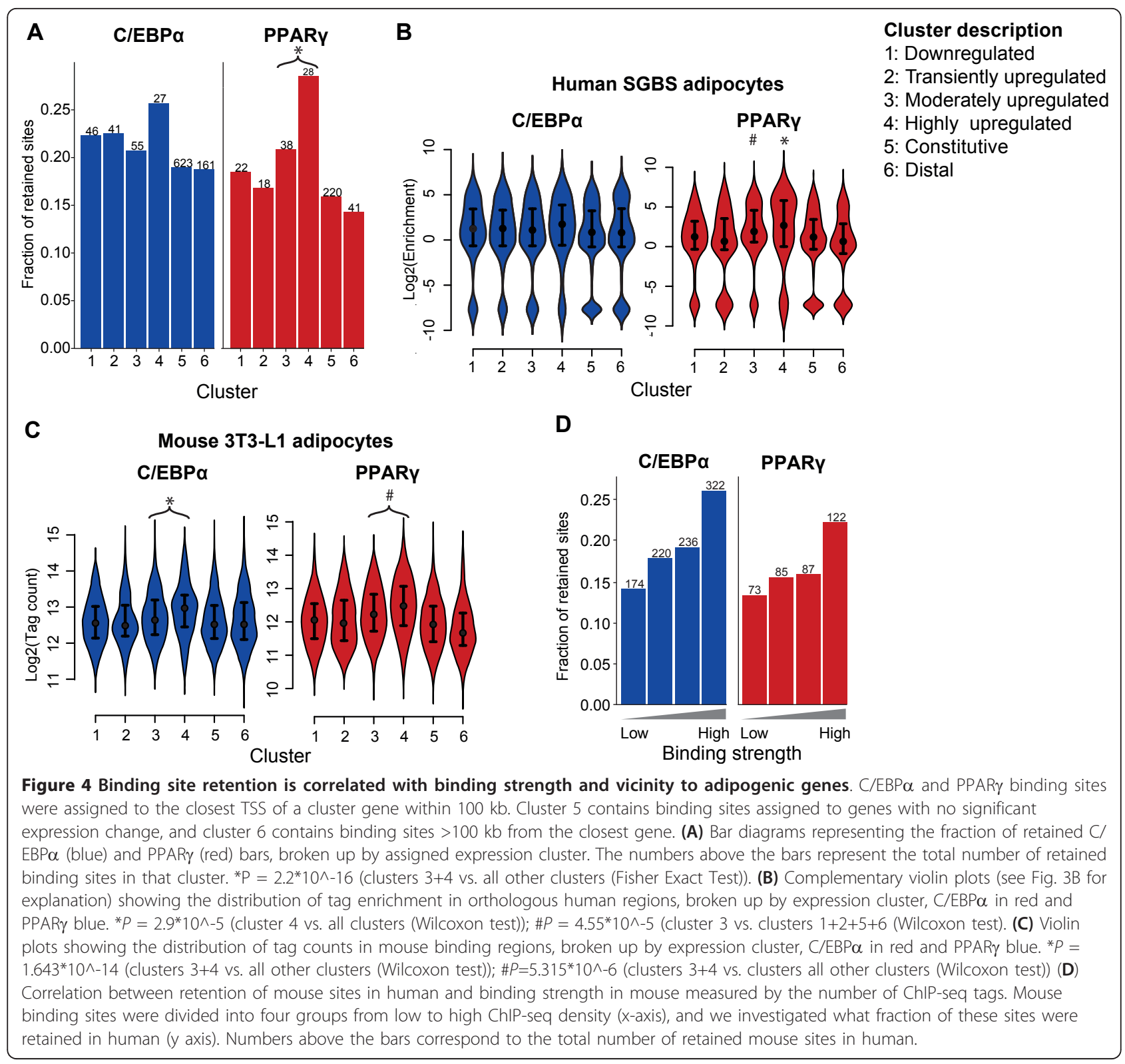

other sites (Wilcoxon test; $\mathrm{C} / \mathrm{EBP} \alpha, P=1.643^{*} 10^{\wedge}-14$; PPAR $\gamma, P=5.315^{*} 10^{\wedge}-6$ ) (Figure $4 C$ ). Thus, target sites in the vicinity of cluster 4 genes are on average bound more strongly by $\mathrm{C} / \mathrm{EBP} \alpha$ and $\mathrm{PPAR} \gamma$ than sites in the vicinity of other genes (Figure $4 \mathrm{~B}$ and $4 \mathrm{C}$ ). This raised the question whether the binding strength in mouse, as measured by the number of ChIP tags, is indicative of binding site retention in human. Therefore, we divided mouse binding sites into quartiles according to binding strength and analyzed retention of $\mathrm{C} / \mathrm{EBP} \alpha$ and PPAR $\gamma$ binding in these subgroups (Figure 4D). Indeed, mouse sites that are strongly bound by either factor are more likely to be retained in human.
Turnover of PPAR $\gamma$ binding is increased in the vicinity of genes upregulated during 3T3-L1 adipogenesis

As discussed above, most mouse sites are not retained in human. However, gene regulation may be retained, if a lost site is replaced by another species-specific site in human nearby the "original" mouse site [31]. We will refer to this scenario as site turnover. Here we defined turnover as a case where a mouse binding site is lost at the corresponding region in human, but compensated by a human-specific site within $10 \mathrm{~kb}$ of the location of the lost site in human. Employing these criteria, we analyzed turnover of $\mathrm{C} / \mathrm{EBP} \alpha$ and PPAR $\gamma$ binding sites assigned to the different gene expression clusters. 
Interestingly, the turnover of PPAR $\gamma$ binding sites is highly increased for sites close to moderately or highly upregulated genes (clusters 3 and 4) (Wilcoxon test, $P=8.183^{*} 10^{\wedge}-4$ ) (Figure 5A). In particular, $>60 \%$ of PPAR $\gamma$ binding sites in the vicinity of highly upregulated genes in mouse adipocytes are either retained or undergo turnover in human adipocytes. Moreover, the highly upregulated genes are much more likely than genes in other clusters to gain multiple human specific PPAR $\gamma$ binding sites in human adipocytes (Figure 5B). By contrast, human-specific C/EBP $\alpha$ sites are found more evenly distributed in the different clusters (Figure $5 \mathrm{~A}+\mathrm{B})$.

\section{Retention of C/EBP $\alpha$ and PPAR $\gamma$ binding is increased at regions bound by both C/EBP $\alpha$ and PPAR $\gamma$}

As discussed above, a large fraction of PPAR $\gamma$ binding sites (36\%) are also bound by C/EBP $\alpha$. To assess the importance of this overlap, we compared the retention of mouse sites that consist of either: i) overlapping
PPAR $\gamma$ and $C / E B P \alpha$ sites, ii) a single PPAR $\gamma$ site or iii) a single $\mathrm{C} / \mathrm{EBP} \alpha$ site (Figure $6 \mathrm{~A}-\mathrm{B}$ ). We will refer to these cases as 'overlapping sites' and PPAR $\gamma$ - or C/EBP $\alpha$-only sites, respectively. The sites in the overlapping group are retained to a higher degree than the other two categories using the binary method (Fisher Exact Test; PPAR $\gamma, P=6.2^{*} 10^{\wedge}-4$; C/EBP $\alpha, P=3.5^{*} 10^{\wedge}-3$ ) (Figure 6B); and this is also true if the enrichment method is used (Wilcoxon test; PPAR $\gamma, P=3.9^{*} 10^{\wedge}-4$; $\mathrm{C} / \mathrm{EBP} \alpha, P=0.007$ ) (Figure $6 \mathrm{C}$ ). Interestingly, the overlapping sites are primarily retained as overlapping sites in human, whereas PPAR $\gamma$-only and C/EBP $\alpha$-only sites are primarily retained as such (Figure 6A-B). However, a few percent of PPAR $\gamma$ and C/EBP $\alpha$-only sites in mouse are detected as overlapping sites in human. We cannot exclude that some of these could be the result of threshold issues in the mouse dataset.

Since we now established that both the expression pattern of nearby genes and co-binding of PPAR $\gamma$ and $\mathrm{C} / \mathrm{EBP} \alpha$ have an impact on retention of sites, we
A

B
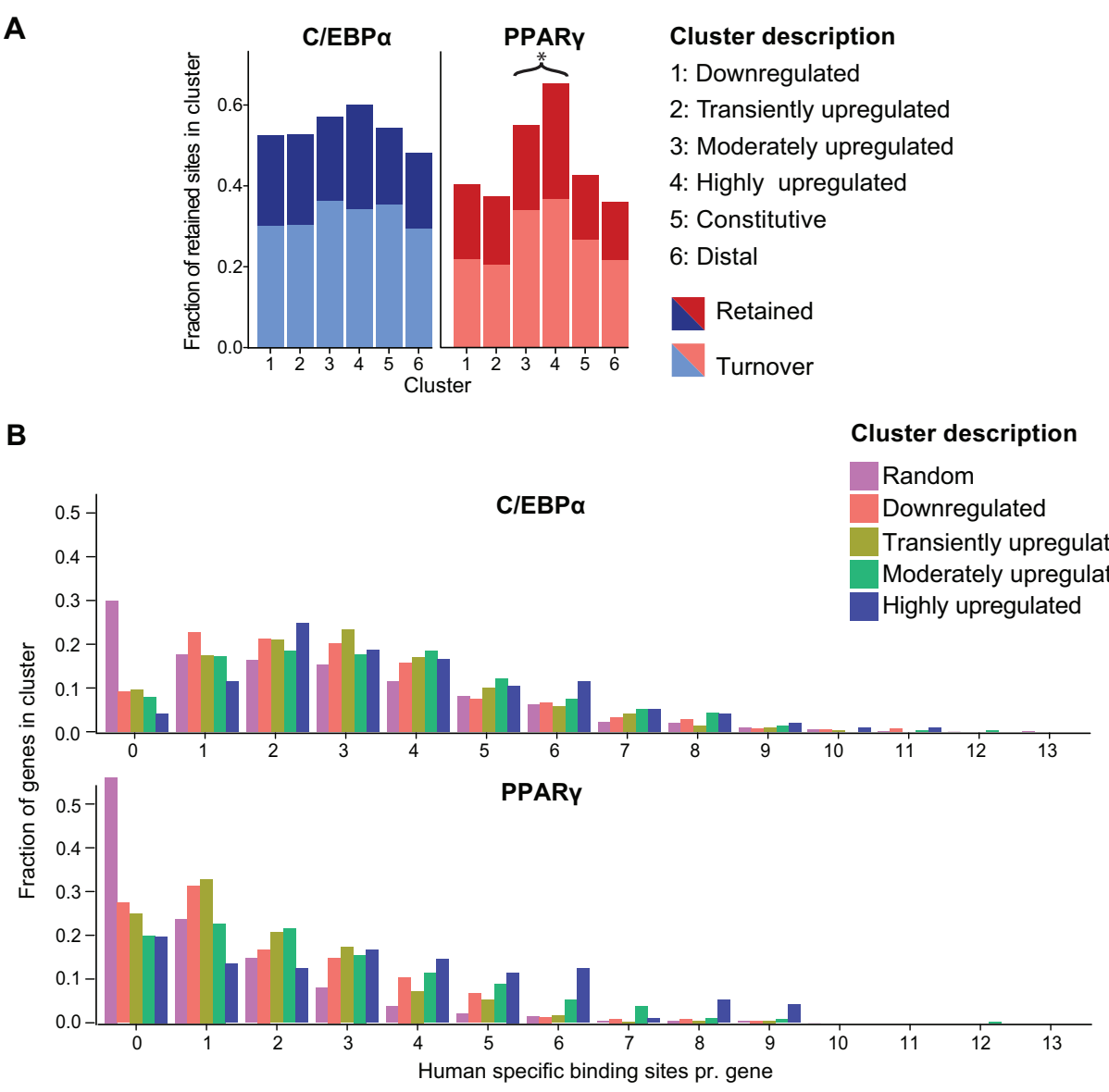

Figure 5 Turnover of binding sites is increased in the vicinity of adipogenic genes. (A) Bar diagrams representing the fraction of transcription factor binding turnover events (C/EBP $\alpha$ : light blue, PPARy: light red) and retained binding sites (C/EBP : blue, PPARy: red) broken up by expression clusters as in Fig. 4. ${ }^{*} P=8.183^{*} 10 \wedge-4$ (clusters $3+4$ vs. all other clusters (Wilcoxon test) (B) Histograms illustrating the fraction (y axis) of human genes within a particular cluster that have the indicated number ( $x$ axis) of human-specific binding sites within 50 kb of the TSS. 


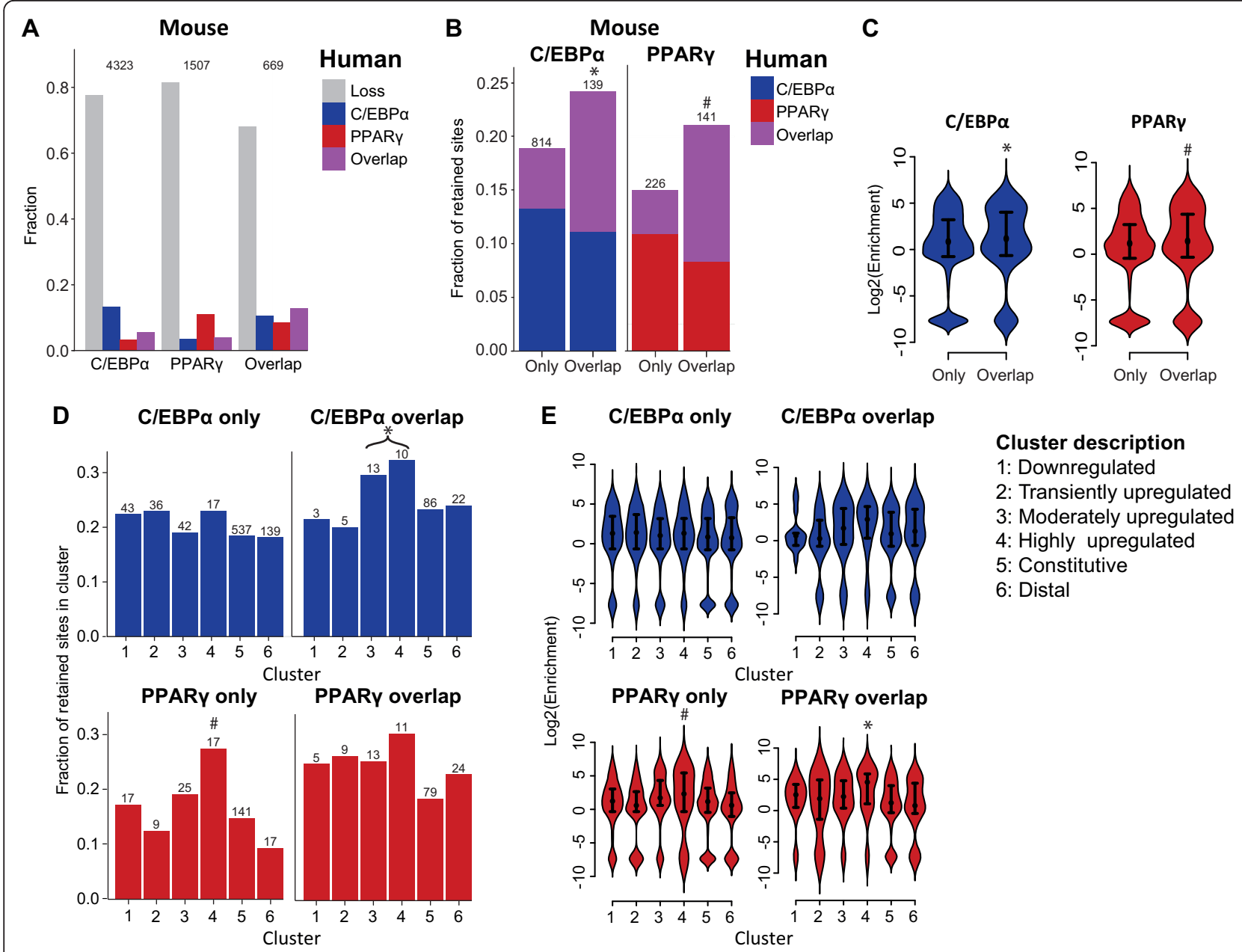

Figure 6 PPAR $\gamma / C / E B P \alpha$ overlap increases retention of binding sites. (A) Bar diagrams illustrating the fraction of C/EBP $\alpha$ only, PPAR $\gamma$ only and overlapping PPAR $\gamma-C / E B P \alpha$ binding sites ( $x$ axis) in mouse mouse that are either lost (gray), or found as a C/EBP $\alpha$ only (blue), PPAR only (red) or PPARy-C/EBPa (purple) binding site in human adipocytes. Numbers above the bars correspond to the total number of mouse sites in each group. (B) Retention of mouse C/EBP $\alpha$ and PPAR $\gamma$ binding sites in mouse adipocytes ( $x$ axis) in the corresponding human regions. The bars represent fractions of mouse binding sites retained as C/EBP $\alpha$-only (blue), PPAR $\gamma$-only (red), and overlap (purple) binding sites in human. The $x$ axis breaks up each set of transcription factor binding sites according to, whether it is C/EBP $\alpha$ - or PPAR $\gamma$-only in mouse, or whether the site is also overlapped with the other factor in mouse. ${ }^{*} P=3.5^{*} 10^{\wedge}-3$ (C/EBP $\alpha$ overlap vs. C/EBP $\alpha$ only (Fisher Exact Test)); \#P=6.2*10^-4 (PPAR $\gamma$ overlap vs. PPARy only (Fisher Exact Test)). (C) Violin plots (see Fig. 3B for explanation) showing the distribution of tag enrichment in orthologous human regions, broken up depending on whether a site is overlapped or not in mouse adipocytes as in Fig. $6 \mathrm{~B}$. ${ }^{*} P=0.007(\mathrm{C} / \mathrm{EBP} \alpha$ overlap vs. C/EBP $\alpha$ only (Wilcoxon test)); \#P = 3.9*10^-4 (PPARy overlap vs. PPARy only (Wilcoxon test)) (D) Retention of C/EBP $\alpha$-only or PPAR $\gamma$-only and PPARy-C/EBP $\alpha$ binding sites in mouse, broken up by expression clusters. ${ }^{*} P=8.6^{*} 10^{\wedge}-15$ (clusters $3+4$ vs. all other clusters (Fisher Exact Test)); $\# P=0.01$ (cluster 4 vs. all other clusters (Fisher Exact Test)). (E) Violin plots showing the distribution of tag enrichment in orthologous human regions, broken up depending on whether a site is overlapped or not and on associated gene cluster in mouse adipocytes. \#P=8.072*10^-3 (cluster 4 vs. All clusters (Wilcoxon test)); ${ }^{*} P=0.001$ (cluster 4 vs. all other clusters (Wilcoxon test)).

proceeded to see how these two associations are depending on one another. About $20 \%$ of C/EBP $\alpha$-only sites are retained in human, regardless of expression pattern of nearby genes (Figure 6D), but C/EBP $\alpha$ binding sites overlapping PPAR $\gamma$ sites have a significantly higher retention if they are in the vicinity of moderately or highly upregulated genes (cluster 3 and 4) (Fisher Exact Test, $\left.P=8.6^{*} 10^{\wedge}-15\right)$. Thus, the increased retention of $\mathrm{C} / \mathrm{EBP} \alpha$ binding in the vicinity of highly upregulated genes (Figure 4A), originates from increased retention of the binding sites that overlap with PPAR $\gamma$ binding.

For PPAR $\gamma$-only sites there are large differences in the amount of retention depending on which gene expression cluster the sites are assigned to, with sites close to highly upregulated genes most likely to be retained (Fisher Exact Test, $P=0.01$ ). By contrast, retention of PPAR $\gamma$ sites overlapping with $\mathrm{C} / \mathrm{EBP} \alpha$ is less affected by 
proximity to highly upregulated genes (Fisher Exact Test, $P=0.2$, PPAR $\gamma$ overlap cluster 4 vs. all other cluster) (Figure 6C). Interestingly, retention of PPAR $\gamma$ sites near highly upregulated genes is not affected by overlap with $\mathrm{C} / \mathrm{EBP} \alpha$ (Fisher Exact Test, $P=0.8179$, PPAR $\gamma$ overlap cluster 4 vs. PPAR $\gamma$ only cluster 4 ). Overall these findings are supported by the enrichment analysis (Figure 6E), although in this case, the enrichment of $\mathrm{C} / \mathrm{EBP} \alpha$ sites that overlap with PPAR $\gamma$ sites near moderately and highly upregulated genes is only close to significant (Wilcoxon test, $P=0.05707$, clusters $3+4$ vs. all other clusters), and the enrichment of PPAR $\gamma$ sites that overlap with C/EBP $\alpha$ sites near highly upregulated genes is now significantly higher than for other PPAR $\gamma$ sites overlapping C/EBP $\alpha$ (Wilcoxon test, $P=0.001$ ).

\section{$\mathrm{C} / \mathrm{EBP} \alpha$ sequence patterns are indicative of PPAR $\gamma$ retention in human but not vice versa}

To further investigate the interdependence of retention of C/EBP $\alpha$ and PPAR $\gamma$ binding at overlapping sites, we wanted to assess whether the presence of predicted binding sites (consensus sites) for the respective factors in human were indicative of retention of mouse binding sites in human. We scanned each of the human regions orthologous to mouse PPAR $\gamma$ and $\mathrm{C} / \mathrm{EBP} \alpha$ binding sites with position weight matrices (PWM) (reviewed in $[32,33]$ ) describing the DNA binding preference of C/EBP $\alpha$ and PPAR $\gamma$. We used thresholds defined by simulation studies (see Methods), and noted whether each binding site had one or more consensus sites for the respective factor. For this analysis, it is important to consider that the consensus site for $\mathrm{C} / \mathrm{EBP} \alpha$ is similar to that of most other members of the C/EBP family. As expected, PPAR $\gamma$-binding sites in mouse are more likely to be retained in human if the corresponding human region has a PPAR $\gamma$ consensus site, and mouse C/EBPa binding sites are also more likely to be retained if their corresponding human regions have a $\mathrm{C} / \mathrm{EBP}$ consensus sites (Fisher Exact Test; C/EBP $\alpha$ only, $P=8.125^{*} 10^{\wedge}-08$; C/EBP $\alpha$ overlap, $P=3.344^{*} 10^{\wedge}-07$; PPAR $\gamma$ only, $P=5.533^{*} 10^{\wedge}-06$; PPAR $\gamma$ overlap, $P=1.935^{*} 10^{\wedge}-06$ ) (Figure 7A).

Interestingly, we found that PPAR $\gamma$ binding sites overlapping $C / E B P \alpha$ sites in mouse are more likely to be retained as PPAR $\gamma$ binding sites in human if they have a C/EBP consensus site (Fisher Exact Test, $P=0.009$ ) (Figure 7B). We noticed the same tendency for PPAR $\gamma$ binding sites not overlapping $\mathrm{C} / \mathrm{EBP} \alpha$ sites in mouse, although this trend is not strong enough to be statistically significant (Fisher Exact Test, $\mathrm{P}=0.16$ ). However, the opposite is not true, i.e. PPAR $\gamma$ consensus sites have no impact on the retention of mouse $\mathrm{C} / \mathrm{EBP} \alpha$ binding sites in human (Fisher Exact, $P=0.88$ ) (Figure 6B).
One way to interpret this is that for regions bound by both factors, the C/EBP consensus site is being selected for over evolution rather than the PPAR $\gamma$ consensus site, which would indicate that PPAR $\gamma$ binding is dependent on sequence-specific C/EBP binding. There are several mechanisms that could explain this, including PPAR $\gamma$ binding to suboptimal sites with the help of C/EBP $\alpha$, indirect binding by tethering to $\mathrm{C} / \mathrm{EBP} \alpha$, and indirect binding via long range chromosomal loops $[34,35]$.

It is likely that in addition to $\mathrm{C} / \mathrm{EBP} \alpha$, several other transcription factors cooperate with PPAR $\gamma$ in the transactivation of nearby genes, and some of these factors may also cooperate with PPAR $\gamma$ in DNA binding. Such cooperativity would be expected to contribute to the retention of PPAR $\gamma$ sites. We investigated how the evolutionary constraint on the overall DNA sequence within the binding region of each mouse PPAR $\gamma$ and $\mathrm{C} / \mathrm{EBP} \alpha$ binding site affects retention of these binding sites in human. We found that regions with high mouse-human DNA sequence identity have higher retention of both C/EBP $\alpha$ and PPAR $\gamma$ binding (Figure $7 C)$. Interestingly, the "high identity quartile" is not enriched for regions containing $\mathrm{C} / \mathrm{EBP} \alpha$ and PPAR $\gamma$ consensus sites (Figure 7D and 7E), indicating that other sequence patterns/transcription factors are also important for retention of C/EBP $\alpha$ and PPAR $\gamma$ binding.

\section{Discussion}

In this study, we used ChIP-seq to generate genomewide profiles of the binding sites of the major adipogenic transcription factors, C/EBP $\alpha$ and PPAR $\gamma$, in mature human SGBS adipocytes. We identified 52,733 $\mathrm{C} / \mathrm{EBP} \alpha$ and 23,328 PPAR $\gamma$ binding sites, and consistent with previous studies in mouse adipocytes $[15,16]$ we found that PPAR $\gamma$ binding sites are highly enriched in the vicinity of genes upregulated during adipogenesis. Furthermore, and also consistent with what has been reported for mouse adipocytes [16], a high percentage (49.5\%) of the PPAR $\gamma$ binding sites overlap with C/EBP $\alpha$ binding sites. Thus, these data indicate conservation of the overall regulatory regime of C/EBP $\alpha$ and PPAR $\gamma$ between mouse and human adipocytes, including their potential direct cooperativity through binding to adjacent sites. However, despite the conservation of the overall regulatory regime and putative target genes between mouse and human adipocytes the retention of mouse binding sites in human is limited, i.e. most sites are species-specific. Similar results demonstrating limited retention of binding sites despite extensive conservation of association with putative functional targets have previously been reported for other transcription factors [20,22-25], and was recently also reported by Rosen and colleagues when comparing PPAR $\gamma$ binding 


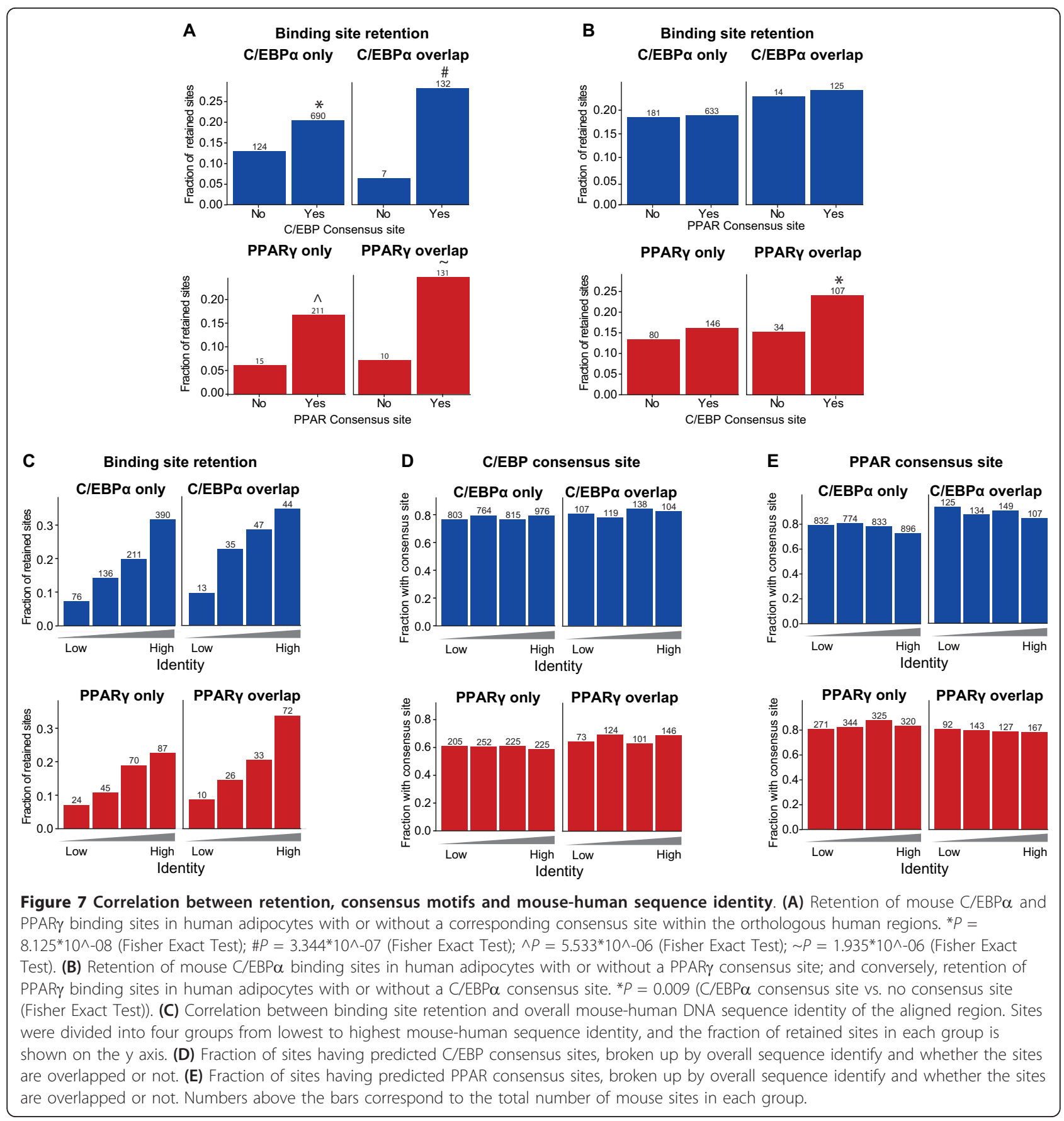

sites in primary human in vitro differentiated adipocytes with the binding sites identified in murine 3T3-L1 cells [21].

Despite the fact that most binding sites of PPAR $\gamma$ and $\mathrm{C} / \mathrm{EBP} \alpha$ are species-specific, there are some sites that we can confidently classify as retained between human and mouse. There are also larger genomic regions, like the PPARG2 locus, where most sites are retained (Figure 3C). This observation prompted us to systematically investigate what biological features determine whether a site is retained or not. Thus, we have systematically investigated several biological features that could affect the retention of mouse C/EBP $\alpha$ and PPAR $\gamma$ binding sites, using two complementary methods with different advantages, i.e. a binary approach where overlaps of sites are counted, and an enrichment approach where the signal strength of human ChIP reads is assessed. The binary approach has the advantage of being conservative (i.e. only strong signals are being labeled as bound sites), and it is easier to interpret the outcomes as sites can be either lost or 
retained. Conversely, the enrichment method can take weaker sites into account and is not dependent on specific thresholds in peak finding; however, this method will not clearly define what sites are retained and lost, as it imposes no thresholds on the data.

Regardless of method, we find that there is a significantly increased retention as well as turn-over of PPAR $\gamma$ binding sites in the vicinity of genes upregulated during adipogenesis compared with binding sites more distant from such genes. By contrast, retention of C/EBP $\alpha$ binding is only slightly increased in the vicinity of genes that are highly upregulated. The difference indicates that there is a higher evolutionary pressure to maintain specific PPAR $\gamma$ binding sites compared with specific $\mathrm{C} / \mathrm{EBP} \alpha$ binding sites for the regulation of adipocyte differentiation and function. This may reflect the higher importance of PPAR $\gamma$ over C/EBP $\alpha$ in adipocyte differentiation, as most clearly demonstrated by Spiegelmann and colleagues, who showed that that ectopic expression of PPAR $\gamma$ in $\mathrm{C} / \mathrm{EBP} \alpha-/$ - mouse embryo fibroblasts (MEF) [36], but not C/EBP $\alpha$ in PPAR $\gamma$-/- MEFs [14], can induce adipogenesis. In addition, since there are more $\mathrm{C} / \mathrm{EBP} \alpha$ binding sites than PPAR $\gamma$ binding sites there may be less evolutionary constraint on the individual C/EBP $\alpha$ sites. This could reflect the lower binding specificity of $C / E B P \alpha$, since it is easier to create a new site if the factor can bind to many different sequences.

We also observed that mouse sites that are strongly bound by either factor are more likely to be retained, but the causality is unclear. Stronger binding sites could be under higher selective pressure, since they are more likely to have a vital function. In addition, stronger binding sites could be harder to erode over time, as these are likely to represent sites where multiple factors such as co-binding transcription factors and chromatin accessibility contribute to a high occupancy of the site. Thus, strongly bound sites in a common ancestor between two species might require more evolutionary changes to be reduced to a fully inactive site in one species.

The remarkable overlap between PPAR $\gamma$ and C/EBP $\alpha$ binding reported previously $[15,16]$ indicates cooperativity between the two transcription factors. In support of this, we find that retention of both C/EBP $\alpha$ and PPAR $\gamma$ binding is increased, when the binding sites overlap with a binding site of the other factor, suggesting that a potential synergy between these two factors is of such significance that selective pressure on these overlapping sites is increased. Interestingly, while retention of $\mathrm{C} / \mathrm{EBP} \alpha$-only sites is not affected by vicinity to regulated genes, the C/EBP $\alpha$ sites that overlap with PPAR $\gamma$ sites display increased retention in the vicinity of upregulated genes, further indicating an importance of C/EBP $\alpha$ cobinding with PPAR $\gamma$ in adipocyte gene regulation.
We also analyzed the sequence of human genomic regions corresponding to overlapping PPAR $\gamma$ and $\mathrm{C} / \mathrm{EBP} \alpha$ binding sites in mouse adipocytes. These analyses revealed that presence of the C/EBP consensus sequence in the human sequence not only predicts the retention of $\mathrm{C} / \mathrm{EBP} \alpha$ binding but, surprisingly, also retention of PPAR $\gamma$ binding at sites that overlap with $\mathrm{C} / \mathrm{EBP} \alpha$ binding sites in mouse. By contrast, the PPAR consensus sequence in the human sequence only predicts retention of PPAR $\gamma$ binding, not retention of C/EBP $\alpha$ binding at sites overlapping with PPAR $\gamma$ binding sites. This indicates that at these overlapping sites, the C/EBP consensus sequence in the binding region is being selected for over evolution to a higher degree than the PPAR consensus site, suggesting that PPAR $\gamma$ binding is directed by $\mathrm{C} / \mathrm{EBP} \alpha$ binding. By analogy, differential binding of nuclear factor $\kappa \mathrm{B}(\mathrm{NF} \kappa \mathrm{B})$ in 10 human individuals correlates with changes in a consensus sites of a reported cooperating transcription factor, signal transducer and activator of transcription 1 (Stat 1) [37], and similar results have been found in studies in yeast [38] and fungi [39].

Possible mechanisms explaining the interdependence between observed C/EBP consensus site conservation and PPAR $\gamma$ retention include C/EBP-assisted binding of PPAR $\gamma$ to an adjacent consensus site as well as indirect binding of PPAR $\gamma$ to DNA by tethering to C/EBP $\alpha$ or by long range intrachromosomal loops [34,35]. Lazar and colleagues have previously investigated the interdependence of C/EBP $\alpha$ and PPAR $\gamma$ binding in mature 3T3-L1 adipocytes and failed to see an effect of C/EBP $\alpha$ knockdown on PPAR $\gamma$ binding to selected target sites in mature 3T3-L1 adipocytes [16]. However, since only a few sites were investigated it is difficult to conclude on the general importance. Furthermore, it is possible that other members of the C/EBP family, which all share the same consensus sequence, play a role in the establishment of the PPAR $\gamma$ transcriptional complex during adipogenesis and a more limited role once the complex is established. Intriguingly, recent data from our laboratory indicate that $C / E B P \beta$, which is expressed early in differentiation, may play a role in early chromatin remodeling of PPAR $\gamma$ binding sites (Siersbæk, Nielsen, John, Sung, Baek, Loft, Hager, and Mandrup, EMBO Journal, in press)).

Odom and colleagues have previously shown that the transcription factor binding regions that were retained between multiple species had higher sequence constraint than species specific binding regions [24], however the interdependence between conservation of the region around the bound site and the retention of the consensus site was not addressed. Interestingly, we show here that the high identity quartile of binding sites (i.e. the binding regions with the highest sequence conservation) displayed increased retention of $\mathrm{C} / \mathrm{EBP} \alpha$ and PPAR $\gamma$ 
binding independent of conservation of their respective consensus sites. This strongly indicates that additional sequence patterns are important for C/EBP $\alpha$ and PPAR $\gamma$ binding. Such sequence patterns could among others be directing binding of cooperating transcription factors.

\section{Conclusions}

Here we have performed a comprehensive and systematic analysis to investigate what parameters affect the retention of transcription factors binding between the mouse and human genome. We show that retention of PPAR $\gamma$ and C/EBP $\alpha$ binding between mouse and human adipocytes is interdependent, which strongly indicates that these transcription factors cooperate at the level of gaining access to their target sites in the genome. In addition, our data show that overall sequence conservation of the binding region contributes to retention, suggesting that other sequence patterns contribute to retention. Future experimental analyses will be required to dissect the interdependence of PPAR $\gamma$ and C/EBP $\alpha$ and possibly other transcription factors at a molecular level.

\section{Methods}

\section{Cell culture}

The 3T3-L1 fibroblasts were differentiated to adipocytes by stimulation with dexamethasone (DEX), 1-methyl-3isobutylxanthine (MIX) and insulin as described previously [40]. The cells were harvested for ChIP experiments at day 6 of differentiation. SGBS cells were generously provided by Dr. Martin Wabitsch at the University of Ulm, Germany and differentiated to adipocytes using a procedure modified from previous publications $[7,41]$. Briefly, SGBS cells were grown to confluence in Dulbecco's Modified Eagle's Medium/Nutrient Mixture F-12 Ham's supplemented with 10\% fetal bovine serum, $33 \mu \mathrm{M}$ biotin, $17 \mu \mathrm{M}$ pantothenate, $100 \mu \mathrm{g} / \mathrm{ml}$ streptomycin, $62.5 \mu \mathrm{g} / \mathrm{ml}$ penicillin, $1 \mathrm{ng} / \mu \mathrm{l}$ fibroblast growth factors (FGF) 1 , and $90 \mu \mathrm{g} / \mu \mathrm{l}$ heparin. At two days postconfluency, SGBS cells were stimulated to differentiate with serum-free growth medium supplemented with $10 \mathrm{nM}$ insulin, $200 \mathrm{pM}$ triiodothyronine, $1 \mu \mathrm{M}$ cortisol, $2 \mu \mathrm{M}$ BRL 49653, $0.115 \mathrm{mg} / \mathrm{ml}$ MIX, $0.25 \mathrm{mmol} / \mathrm{L}$ DEX, and $0.01 \mathrm{mg} / \mathrm{ml}$ human transferrin. After 3 days, the medium was replaced with the differentiation medium without FGF1 and heparin, and after 6 days Rosiglitazone/BRL49653, MIX, and DEX was removed from the medium. The cells were harvested for ChIP experiments at day 10 of differentiation.

\section{ChIP-seq}

ChIP experiments were performed according to standard protocol as described in [42]. Antibodies used were: PPAR $\gamma$ (H-100, sc7196, Santa Cruz), C/EBP $\alpha$ (14AA, sc61). ChIP-seq sample preparation for sequencing was performed according to the manufacturer's instructions (Illumina). Sequence reads from each ChIPseq library were mapped to the reference genomes $\mathrm{mm} 9$ for mouse and hg18 for human using the the BWA alignment software allowing for 2 mismatches [43]. PPAR $\gamma$ and C/EBP $\alpha$ binding sites were identified using MACS [29] with a p-value cutoff of $\mathrm{e}^{-10}$, and using sonicated input as a control. C/EBP $\alpha$ and PPAR $\gamma$ ChIP-seqs in 3T3-L1 were performed in monoplicates, and to identify high confidence binding sites we compared our data with previously published C/EBP $\alpha$ and PPAR $\gamma$ ChIPchip data [16]. ChIP-seq binding regions overlapped by ChIP-chip binding regions were used for downstream analysis. C/EBP $\alpha$ and PPAR $\gamma$ ChIP-seqs in SGBS cells were performed in duplicates from two independent experiments, and binding sites identified in both experiments were used for downstream analysis. Some of the detected sites both in SGBS and 3T3-L1 cells were much wider than expected, possibly due to multiple nearby binding events or noise. To avoid these and focus on reliable sites, we filtered away the $5 \%$ widest binding sites.

\section{Finding regions bound by both PPAR $\gamma$ and C/EBP $\alpha$}

Initial analysis of the overlap between C/EBP $\alpha$ and PPAR $\gamma$ binding sites in mouse showed that in the large majority of cases either most of the site of one factor is overlapped by the site of the other factor or it is not overlapped at all (Additional file 1 Fig. S2). Thus, altering the threshold for how large the overlap should be for sites to be considered overlapping, does not have substantial impact of the downstream analysis. Based on the percentage overlap shown in Additional file 1 Fig. S2 and the length distributions for the binding sites in mouse, a C/EBP $\alpha$ site overlapping a PPAR $\gamma$ site with at least $1 \%$ of the total width of the C/EBP $\alpha$ site was defined as "overlapping". The PPAR $\gamma$ binding sites are in general more narrow than $\mathrm{C} / \mathrm{EBP} \alpha$, so we used a higher threshold of $10 \%$ overlap for PPAR $\gamma$. In human regions corresponding to mouse sites we relaxed this criterion to $1 \mathrm{nt}$ overlap, since there is an implicit criterion for both sites to be in the same region in the orthology analysis described below. Changing the criteria lead to no substantial difference in terms of overall results (data not shown).

\section{Finding human genomic regions orthologous to the mouse binding sites}

We used the UCSC lift over tool $[44,45]$ together with chained BlastZ alignments [30] to lift over the binding sites from $\mathrm{mm} 9$ to hg18 genome assemblies. We used 
minMatch $=0.1$, which is the recommended setting for inter-species comparisons. We then lifted the binding sites back again and tested if they overlapped a minimum of $90 \%$ of the original region. Only binding sites that could be uniquely mapped both ways were considered for the rest of the analyses.

\section{Defining retained, species-specific binding sites and turnover events}

For each lifted mouse binding site we checked if $>10 \%$ of the site was overlapped by a human site, or vice versa. If any of these criteria were true, the mouse site was considered retained. Mouse binding sites that were not retained was considered specific to mouse and lost in human. In the same way, human binding sites that are not overlapped $10 \%$ by a lifted mouse binding site or vice versa were considered specific to human.

A lost binding site may have been replaced with a new, species-specific binding site - i.e. binding site turnover. For the binding sites lost in human, we checked if a human-specific binding site is located $+/-10 \mathrm{~kb}(\max 10 \mathrm{~kb}$ between the midpoints of the two binding sites) from the original lifted binding site. If this was the case, the site was considered subject to a turnover event.

\section{Calculating ChIP-seq enrichment in human}

As a complementary approach to the above, we considered ChIP-seq counts in human regions orthologous to mouse binding sites as a continuous variable rather than counting the overlap of human ChIP-seq peaks defined by the peak finder. This makes sense, as the number of ChIP-seq tags should correspond to the binding strength of a respective factor.

To make this comparable across regions, for a human region defined as orthologous to a mouse binding site, we counted the number of human ChIP tags in a window centered on the region with a window width corresponding to the $75^{\text {th }}$ percentile of all human binding sites, for the respective factor: $520 \mathrm{nt}$ for $\mathrm{C} / \mathrm{EBP} \alpha$ and $605 \mathrm{nt}$ for PPAR $\gamma$. We then estimated the number of ChIP-seq tags expected by random by calculating the mean ChIP-seq counts of 2000 randomly sampled genomic regions with the same widths as above. A $\log _{2}$ fold change value was calculated by dividing the observed number of ChIP-seq tags in the orthologous region with the random expectation. To avoid small number effects, we added a pseudo-count of 1 to both random regions and observed binding site counts.

\section{Assigning genes and expression clusters to mouse binding sites}

For each binding site we identified all genes (knownGene table from UCSC genome browser database [46]), where the TSS is located $+/-100 \mathrm{~kb}$ from the center of the binding site. The binding site was labeled with the label of the closest gene that was part of an expression cluster. If none of the nearby genes were in a cluster, the binding site was placed in cluster 5 ("constitutive genes"); whereas the site was considered to belong to cluster 6 ("distal sites") if there were no TSS within $100 \mathrm{~kb}$ of the binding site.

\section{Finding human gene orthologs to the differentially expressed mouse genes}

For each differentially expressed mouse gene we used the UCSC lift over tool together with chained BlastZ alignments to lift over the TSS $+/-50$ bp from $\mathrm{mm} 9$ to hg18. We then found the closest gene (knownGene table from UCSC) within $5 \mathrm{~kb}$ of the lifted TSS. Using this method we found orthologous genes for 1482 of the 1626 mouse genes. We discarded from further analyses the 113 TSS regions that could not be lifted, and the 49 of the lifted TSSs that were not located in proximity $(+/-5 \mathrm{~kb})$ of any UCSC human gene.

\section{Sequence content analysis}

We scanned both strands of each human region defined above with position weight matrices (PWMs) (reviewed in [32]) from the JASPAR database (models MA0065.2 and MA0019.1, respectively, for PPAR $\gamma$ and $\mathrm{C} / \mathrm{EBP} \alpha$ ) using the ASAP tool [47] based on a background model following a uniform distribution. To decide a relevant threshold for accepting a predicted binding site, we repeated the analysis in randomly selected regions with the respective PWM. A threshold of $80 \%$ of the scoring range of each model could separate the ChIP'ed regions and random regions best, so we used this for further analysis.

\section{Calculating human-mouse identity}

According to the binding sites in mouse described above, we extracted the alignments between mouse and human by mafFrag from the Kent source utilities http://genomewiki.ucsc.edu. We then applied Alistat, a utility included in the HMMER package, http://hmmer. janelia.org/ to calculate the identity score defined as (\#Identity/minimum (length1, length2)), where \#identity is the number of exact identities in an alignment and length1, length2 are the unaligned lengths of the two sequences.

\section{Data availability}

Raw sequencing reads, aligned reads, wiggle files, and MACS regions for all ChIP-seq samples described here have been deposited to the NCBI GEO database http:// www.ncbi.nlm.nih.gov/geo/ under accession number GSE27450. 


\section{Additional material}

$$
\text { Additional file 1: Fig. S1+2.pdf }
$$

\section{Abbreviations}

C/EBP: CAAT/enhancer binding protein; ChIP: chromatin immunoprecipitation; hASC: human adipose stromal cells; MEF: mouse embryo fibroblast; PPAR: peroxisome proliferator activated receptor; PWM position weight matrices; RNAPII: RNA polymerase II; RXR: retinoid $\times$ receptor; SGBS: Simpson Golabi Sehmel syndrom; TSS: Transcription start site.

\section{Acknowledgements}

The authors thank members of the Mandrup and Sandelin laboratories for valuable discussions and input to the manuscript. We are grateful to Dr. Martin Wabitsch, University of UIm for the human SGBS cells. This work was supported by grants to SM from the Novo Nordisk Foundation and the NIH NIDDK/ODS (5R01-DK063070) and by grants from European Research Council (FP7/20072013/ERC grant agreement 204135) and the Novo Nordisk Foundation to AS.

\section{Author details}

${ }^{1}$ Department of Biochemistry and Molecular Biology, University of Southern Denmark, Campusvej 55, DK-5230 Odense M, Denmark. ${ }^{2}$ The Bioinformatics Centre, Department of Biology and Biomedical Research and Innovation Centre, Copenhagen University, Ole Maaløs Vej 5, DK-2200, Copenhagen N, Denmark.

\section{Authors' contributions}

SM, SFS, and AS conceived and designed the study. SFS performed all biological experiments except for deep sequencing, which was performed by RN. MJ and YC performed all computational analysis with help from AS. SFS, MJ, YC and AS made all figures. SFS, SM, AS, MJ and YC wrote the manuscript. All authors read and approved the manuscript.

Received: 23 December 2010 Accepted: 16 March 2011

Published: 16 March 2011

\section{References}

1. Guilherme A, Virbasius JV, Puri V, Czech MP: Adipocyte dysfunctions linking obesity to insulin resistance and type 2 diabetes. Nat Rev Mol Cell Biol 2008, 9:367-377.

2. Rosen ED, Spiegelman BM: Adipocytes as regulators of energy balance and glucose homeostasis. Nature 2006, 444:847-853

3. Green H, Kehinde O: Sublines of Mouse 3T3 Cells That Accumulate Lipid. Cell 1974, 1:113-116.

4. MacDougald OA, Mandrup S: Adipogenesis: forces that tip the scales. Trends Endocrinol Metab 2002, 13:5-11.

5. Rosen ED, MacDougald OA: Adipocyte differentiation from the inside out. Nat Rev Mol Cell Biol 2006, 7:885-896.

6. Farmer SR: Transcriptional control of adipocyte formation. Cell Metab 2006, 4:263-273

7. Wabitsch M, Brenner RE, Melzner I, Braun M, Moller P, Heinze E, et al: Characterization of a human preadipocyte cell strain with high capacity for adipose differentiation. Int J Obes Relat Metab Disord 2001 25:8-15

8. Rosen ED, Sarraf P, Troy AE, Bradwin G, Moore K, Milstone DS, et al: PPAR gamma is required for the differentiation of adipose tissue in vivo and in vitro. Molecular Cell 1999, 4:611-617.

9. Barak Y, Nelson MC, Ong ES, Jones YZ, Ruiz-Lozano P, Chien KR, et al: PPAR gamma is required for placental, cardiac, and adipose tissue development. Molecular Cell 1999, 4:585-595.

10. Wang Nd, Milton JF, Bradley A, Ou CN, Abdelsayed SV, Wilde MD, et al: Impaired Energy Homeostasis in C/EBPalpha Knockout Mice. Science 1995, 269:1108-1112.

11. Linhart HG, Ishimura-Oka K, DeMayo F, Kibe T, Repka D, Poindexter B, et al: C/EBPalpha is required for differentiation of white, but not brown, adipose tissue. Proceedings of the National Academy of Sciences of the United States of America 2001, 98:12532-12537.
12. Tanaka T, Yoshida N, Kishimoto T, Akira S: Defective adipocyte differentiation in mice lacking the C/EBPbeta and/or C/EBPdelta gene. EMBO J 1997, 16:7432-7443.

13. Wu Z, Rosen ED, Brun R, Hauser S, Adelmant G, Troy AE, et al: Crossregulation of C/EBP alpha and PPAR gamma controls the transcriptional pathway of adipogenesis and insulin sensitivity. Mol Cell 1999, 3:151-158

14. Rosen ED, Hsu CH, Wang X, Sakai S, Freeman MW, Gonzalez FJ, et al: C/EBPalpha induces adipogenesis through PPARgamma: a unified pathway. Genes Dev 2002, 16:22-26.

15. Nielsen R, Pedersen TA, Hagenbeek D, Moulos P, Siersbaek R, Megens E, et al: Genome-wide profiling of PPARgamma:RXR and RNA polymerase II occupancy reveals temporal activation of distinct metabolic pathways and changes in RXR dimer composition during adipogenesis. Genes Dev 2008, 22:2953-2967.

16. Lefterova MI, Zhang Y, Steger DJ, Schupp M, Schug J, Cristancho A, et al: PPARgamma and C/EBP factors orchestrate adipocyte biology via adjacent binding on a genome-wide scale. Genes Dev 2008, 22:2941-2952.

17. Hamza MS, Pott S, Vega VB, Thomsen JS, Kandhadayar GS, Ng PW, et al: Denovo identification of PPARgamma/RXR binding sites and direct targets during adipogenesis. PLoS One 2009, 4:e4907.

18. Wakabayashi K, Okamura M, Tsutsumi S, Nishikawa NS, Tanaka T, Sakakibara I, et al: The peroxisome proliferator-activated receptor gamma/retinoid $\times$ receptor alpha heterodimer targets the histone modification enzyme PR-Set7/Setd8 gene and regulates adipogenesis through a positive feedback loop. Mol Cell Biol 2009, 29:3544-3555.

19. Siersbaek R, Nielsen R, Mandrup S: PPARgamma in adipocyte differentiation and metabolism-novel insights from genome-wide studies. FEBS Lett 2010, 584:3242-3249.

20. Boj SF, Servitja JM, Martin D, Rios M, Talianidis I, Guigo R, et al: Functional targets of the monogenic diabetes transcription factors HNF-1alpha and HNF-4alpha are highly conserved between mice and humans. Diabetes 2009, 58:1245-1253.

21. Mikkelsen TS, Xu Z, Zhang X, Wang L, Gimble JM, Lander ES, et al: Comparative epigenomic analysis of murine and human adipogenesis. Cell 2010, 143:156-169.

22. Kunarso G, Chia NY, Jeyakani J, Hwang C, Lu X, Chan YS, et al: Transposable elements have rewired the core regulatory network of human embryonic stem cells. Nat Genet 2010, 42:631-634.

23. Odom DT, Dowell RD, Jacobsen ES, Gordon W, Danford TW, Maclsaac KD, et al: Tissue-specific transcriptional regulation has diverged significantly between human and mouse. Nat Genet 2007, 39:730-732.

24. Schmidt D, Wilson MD, Ballester B, Schwalie PC, Brown GD, Marshall A, et al: Five-vertebrate ChIP-seq reveals the evolutionary dynamics of transcription factor binding. Science 2010, 328:1036-1040.

25. Wilson MD, Barbosa-Morais NL, Schmidt D, Conboy CM, Vanes L, Tybulewicz $V L$, et al: Species-specific transcription in mice carrying human chromosome 21. Science 2008, 322:434-438.

26. Wilson MD, Odom DT: Evolution of transcriptional control in mammals. Curr Opin Genet Dev 2009, 19:579-585

27. Wasserman WW, Palumbo M, Thompson W, Fickett JW, Lawrence CE: Human-mouse genome comparisons to locate regulatory sites. Nat Genet 2000, 26:225-228.

28. Lenhard B, Sandelin A, Mendoza L, Engstrom P, Jareborg N, Wasserman WW: Identification of conserved regulatory elements by comparative genome analysis. J Biol 2003, 2:13.

29. Zhang Y, Liu T, Meyer CA, Eeckhoute J, Johnson DS, Bernstein BE, et al: Model-based analysis of ChIP-Seq (MACS). Genome Biol 2008, 9:R137.

30. Schwartz S, Kent WJ, Smit A, Zhang Z, Baertsch R, Hardison RC, et al: Human-mouse alignments with BLASTZ. Genome Res 2003, 13:103-107.

31. Dermitzakis ET, Clark AG: Evolution of transcription factor binding sites in Mammalian gene regulatory regions: conservation and turnover. $\mathrm{Mol} \mathrm{BiO}$ Evol 2002, 19:1114-1121.

32. Wasserman WW, Sandelin A: Applied bioinformatics for the identification of regulatory elements. Nat Rev Genet 2004, 5:276-287.

33. Stormo GD: DNA binding sites: representation and discovery. Bioinformatics 2000, 16:16-23.

34. Fullwood MJ, Liu MH, Pan YF, Liu J, Xu H, Mohamed YB, et al: An oestrogen-receptor-alpha-bound human chromatin interactome. Nature 2009, 462:58-64. 
35. Carroll JS, Liu XS, Brodsky AS, Li W, Meyer CA, Szary AJ, et al: Chromosomewide mapping of estrogen receptor binding reveals long-range regulation requiring the forkhead protein FoxA1. Cell 2005, 122:33-43.

36. Wu Z, Rosen ED, Brun R, Hauser S, Adelmant G, Troy AE, et al: Crossregulation of C/EBP alpha and PPAR gamma controls the transcriptional pathway of adipogenesis and insulin sensitivity. Mol Cell 1999, 3:151-158.

37. Kasowski M, Grubert F, Heffelfinger C, Hariharan M, Asabere A, Waszak SM, et al: Variation in transcription factor binding among humans. Science 2010, 328:232-235.

38. Zheng W, Zhao H, Mancera E, Steinmetz LM, Snyder M: Genetic analysis of variation in transcription factor binding in yeast. Nature 2010, 464:1187-1191.

39. Tuch BB, Galgoczy DJ, Hernday AD, Li H, Johnson AD: The evolution of combinatorial gene regulation in fungi. PLoS Biol 2008, 6:e38.

40. Helledie T, Grontved L, Jensen SS, Killerich P, Rietveld L, Albrektsen T, et al: The gene encoding the Acyl-CoA-binding protein is activated by peroxisome proliferator-activated receptor gamma through an intronic response element functionally conserved between humans and rodents. J Biol Chem 2002, 277:26821-26830.

41. Newell FS, Su H, Tornqvist H, Whitehead JP, Prins JB, Hutley L: Characterization of the transcriptional and functional effects of fibroblast growth factor- 1 on human preadipocyte differentiation. FASEB J 2006, 20:2615-2617.

42. Nielsen R, Grontved L, Stunnenberg HG, Mandrup S: Peroxisome proliferator-activated receptor subtype- and cell-type-specific activation of genomic target genes upon adenoviral transgene delivery. Mol Cell Biol 2006, 26:5698-5714.

43. Li H, Durbin R: Fast and accurate short read alignment with BurrowsWheeler transform. Bioinformatics 2009, 25:1754-1760.

44. Fujita PA, Rhead B, Zweig AS, Hinrichs AS, Karolchik D, Cline MS, et al: The UCSC Genome Browser database: update 2011. Nucleic Acids Res 2010.

45. Kent WJ, Sugnet CW, Furey TS, Roskin KM, Pringle TH, Zahler AM, et al: The human genome browser at UCSC. Genome Res 2002, 12:996-1006.

46. Hsu F, Kent WJ, Clawson H, Kuhn RM, Diekhans M, Haussler D: The UCSC Known Genes. Bioinformatics 2006, 22:1036-1046.

47. Marstrand TT, Frellsen J, Moltke I, Thiim M, Valen E, Retelska D, et al: Asap: a framework for over-representation statistics for transcription factor binding sites. PLoS One 2008, 3:e1623.

48. Hintze JL, Nelson RD: Violin plots: A box plot-density trace synergism. American Statistician 1998, 52:181-184.

doi:10.1186/1471-2164-12-152

Cite this article as: Schmidt et al: Cross species comparison of C/EBPo and PPAR $\gamma$ profiles in mouse and human adipocytes reveals interdependent retention of binding sites. BMC Genomics 2011 12:152.

\section{Submit your next manuscript to BioMed Central and take full advantage of:}

- Convenient online submission

- Thorough peer review

- No space constraints or color figure charges

- Immediate publication on acceptance

- Inclusion in PubMed, CAS, Scopus and Google Scholar

- Research which is freely available for redistribution

Submit your manuscript at www.biomedcentral.com/submit
Biomed Central 